\title{
Rubbish or resources: an investigation of converting municipal solid waste (MSW) to bio-ethanol production
}

\author{
A. Li \& M. Khraisheh \\ University College London, \\ Department of Civil, Environmental and Geomatic Engineering, \\ Gower Street, London, UK
}

\begin{abstract}
An investigation into the possibility of replacing conventional biomass with biodegradable municipal solid waste (BMSW), which provides an alternative solution for preventing organic fraction of municipal solid waste going into landfill required by EU Landfill Directives (European Commission [1]) was carried out. The experimental results have shown that more than $85 \%$ of the cellulose from the waste can be converted to glucose, which can be easily fermented to ethanol production. The conversion rate is relatively high compared with other conventional biomass. Taking into account the existing waste collection system and the cost for disposing of waste, makes this waste-toethanol system economically valuable. However, every type of energy has some advantages as well as disadvantages. This paper identifies the potential impacts of using BMSW as bio-ethanol resources from the prospects of both energy development and waste management. The opportunities of MSW-to-ethanol as an alternative waste management are also discussed with the recommendation for further life cycle study.

Keywords: biodegradable municipal solid waste (BMSW), MSW-bioethanol, environmental impact, life cycle assessment.
\end{abstract}

\section{Introduction}

The use of bio-fuel for transport is becoming of increasing importance for a number of reasons, such as environmental concerns relating to climate change, 
depletion of fossil fuel reserves, and reduction of reliance on imports. On the other hand, European legislative pressures target for minimizing landfill use: the amount of biodegradable municipal solid waste (BMSW) going to landfill must be reduced by $25 \%$ by $2010,50 \%$ by 2013 and $65 \%$ by 2010 . Thus, an alternative way of disposing of BMSW needs to be investigated.

London Boroughs (UK) collected 4.4 thousand tones of total municipal solid waste (MSW) in 2004-2005 (Defra [2]). Among of the waste generated, about $73 \%$ goes to landfill and $17 \%$ to incineration. This study investigates the possibility of replacing the conventional biomass with biodegradable municipal solid waste, which provides an alternative solution for preventing the organic fraction of municipal solid waste going into landfill and producing bio-ethanol production for the renewable energy market demand and discusses the potential environmental impacts of this process.

The process of converting BMSW to ethanol is shown in figure 1. Prehydrolysis treatment and enzymatic hydrolysis of BMSW are of crucial importance during the bioconversion of BMSW-to-bio-ethanol, and thus their optimization will result in beneficial environmental and economic practices (Wyman [3]). Previous study has investigated the impact of pre-hydrolysis treatments (i.e., dilute acid type and concentration, steam treatment, microwave) and enzymatic hydrolysis (i.e., enzyme type and concentration) on the bioconversion of BMSW-to-glucose at laboratory-scale (Li [4]). This study is to continue the previous research and optimize the processes by using mixed municipal solid waste for bio-ethanol production and bio-ethanol technology.

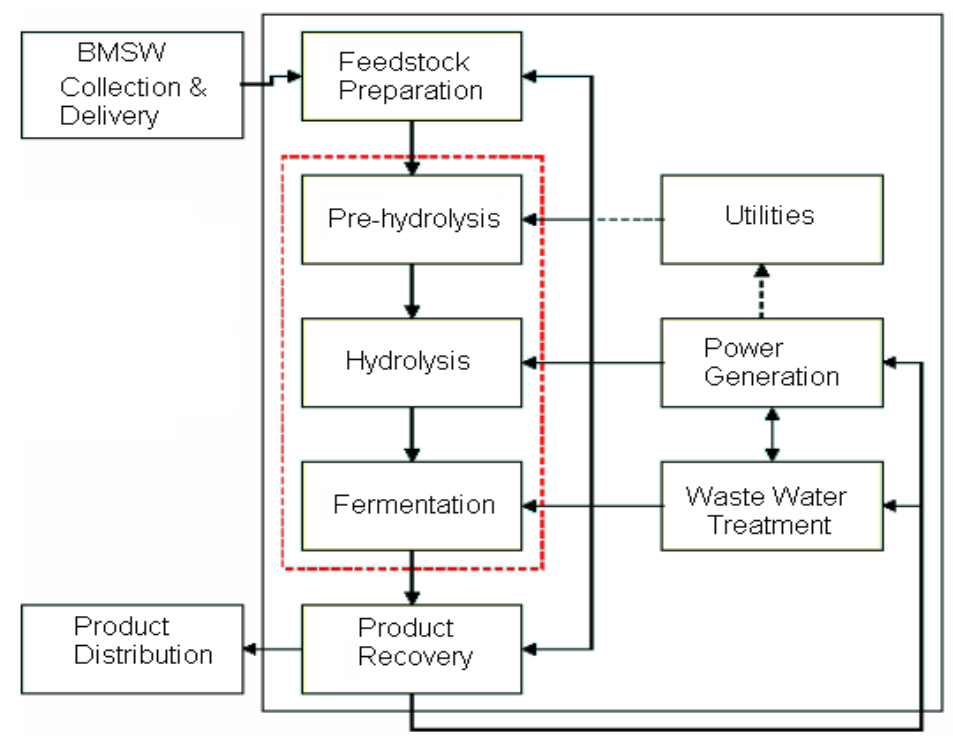

Figure 1: BMSW-to-bioethanol process. 


\section{Materials and methods}

The BMSW-to-ethanol process is shown in figure 1 which includes sample collection, pre-treatment, hydrolysis, fermentation, product recovery ad product distribution. The BMSW used in this study was selected from typical biodegradable waste, such as kitchen waste, garden waste and paper waste. The sample consists of $20 \%$ carrot peelings, $20 \%$ potato peelings, $20 \%$ grass, $20 \%$ newspaper, and $20 \%$ scrap paper. The selected waste was milled to small particles with size of $0.2 \mathrm{~mm}-1.2 \mathrm{~mm}$, and then followed by pre-hydrolysis with sulphuric acid and steam treatment, and then enzymatic hydrolysis.

\subsection{Pre-hydrolysis treatment}

Biomass and dilute sulphuric acid (1\%) were mixed at a solid/ liquid ratio of 0.5 $\mathrm{g}$ in $50 \mathrm{ml}$. The acid-soaked samples were then placed in an autoclave at a constant temperature $121^{\circ} \mathrm{C}$ for 60 minutes. Following steam treatment, the samples were washed with deionised water until the $\mathrm{pH}$ of the filtrate remained constant at an approximate value of 4.5. The pre-treated samples were drained and air-dried overnight to a final $45 \%$ moisture content.

\subsection{Enzymatic hydrolysis}

Enzymatic hydrolysis of pre-hydrolysed substrate was carried out within the study temperature range in vials $(50 \mathrm{ml})$ placed in an orbital agitator at $68 \mathrm{rpm}$ for $24 \mathrm{~h}$. The liquor $\mathrm{pH}$ was adjusted using $0.1 \mathrm{M}$ citrate acid-sodium citrate buffer. Enzymes, T. viride (Sigma, UK) were used as received in combination with the enzyme beta-glucosidase (Sigma, UK). The cellulase activity of the enzymes (Melander [5]) was measured by the Filter Paper assay developed by Mandels [6], and the activity was expressed in terms of Filter Paper Units (FPU). The b-glucosidase activity was measured by the PNPG assay (Paquot [7]), and reported as PNPG units (PNPGU). Samples were withdrawn from the reaction media after $24 \mathrm{~h}$.

\subsection{Analytical methods}

Sugar concentrations were determined routinely from centrifuged samples (13,000 rpm, $5 \mathrm{~min}$ ) using HPLC (Perkin-Elmer Ltd, UK). All compositional analyses were done in triplicate, and data were corrected to a $100 \%$ dry matter (DM) basis. Glucose yield as a percentage of the theoretical yield [percentage digestibility, obtained from the equation which involves the transfer of cellulose to sugar $\left.\left(\mathrm{C}_{6} \mathrm{H}_{10} \mathrm{O}_{5}\right)_{\mathrm{n}}+\mathrm{nH}_{2} \mathrm{O}=\left(\mathrm{C}_{6} \mathrm{H}_{12} \mathrm{O}_{6}\right) \mathrm{n}\right]$ was computed by using the formula given by the National Renewable Energy Laboratory (Standard Biomass Analytical Procedures) (NREL [8]). A factorial experimental design with the software package Design Ease 6.0.6 (Stateease, Inc.) was used in this study. Selected factors identified as more convenient to control the hydrolysis process were selected from enzymatic hydrolysis. The relevant factors with the study range are shown in Table 1. 
The mass balances were calculated for two main steps: 1- from raw material to pre-hydrolysed biomass, and 2-to enzymatic hydrolysis residues, with consideration of the weight loss during each step.

The environmental impact assessment is based on the results from laboratory work. The assessment covers a number of environmental issues such as waste management, carbon dioxide emission, water issue, land-use, and biodiversity etc, by comparing with traditional biomass such as corn and energy crops.

Table 1: $\quad$ Study factors for the enzymatic hydrolysis process.

\begin{tabular}{|l|l|}
\hline Factor & Study range \\
\hline A: Particle size & $2-20 \mathrm{~mm}$ \\
\hline B: Substrate concentration & $5-15 \mathrm{~g} / 1$ \\
\hline C: Enzyme loading & $10-100 \mathrm{FPU}$ \\
\hline D: Beta-glucosidase & $10-100$ PNPGU g-1 \\
\hline E: $\mathrm{pH}$ & $3.7-5.0$ \\
\hline F: Temperature & $37-50{ }^{\circ} \mathrm{C}$ \\
\hline
\end{tabular}

\section{Experimental results and discussion}

Previous study (Li [4]) showed that BMSW as a feedstock produced about 52\% glucose for the production of ethanol. Recent studies on hydrolysis optimization showed about $85 \%$ glucose yield can be reached under the optimal conditions (lower substrate concentration, lower beta-glucosidase loading, and temperature $50^{\circ} \mathrm{C}$ ) (figure 2).

The contribution of substrate concentration to the glucose yield was significantly higher $(93.6 \%)$, than the contribution of temperature $(3.2 \%)$ and beta-glucosidase loading $(2.6 \%)$. Other factors such as particle size, enzyme loading, and $\mathrm{pH}$ have very little effect on the glucose yield within the study range. The results obtained by the model presented a satisfactory correlation to the actual values $(\mathrm{R} 2=0.90)$. Additionally, this study indicated that lower substrate concentration $(5 \mathrm{~g} / \mathrm{l})$, higher temperature $\left(50^{\circ} \mathrm{C}\right)$ and less betaglucosidase produced the highest glucose yields. The significant contribution of substrate concentration and temperature at $50^{\circ} \mathrm{C}$ has met the agreement with other studies on conventional biomass (Ballesteros [9]). The reason for less betaglucosidase may be concluded as the inhibition of the enzyme as suggested by Gregg [10]. This study indicated that BMSW fractions did not require higher cellulase loadings to obtain high glucose yields, which can reduce the cost of the process.

Results from the mass balance revealed that about $0.25 \mathrm{~g}$ biomass remained after pre-hydrolysis and $0.1 \mathrm{~g}$ remained after the enzymatic hydrolysis process when $0.5 \mathrm{~g}$ BMSW was used as feedstock. This indicated that about $80 \%$ of the biodegradable waste fractions were removed by using this BMSW-to-ethanol process. 


\section{Environmental impacts}

The environmental impacts were assessed from the following areas: waste management, climate change, water issues, land use, biodiversity and others.

(a)

\begin{tabular}{lc}
\hline Factor & $\%$ Contribution \\
\hline B - Substrate Concentration & 93.6 \\
D - Beta-glucosidase & 2.6 \\
F - Temperature & 3.2 \\
\hline
\end{tabular}

(b)
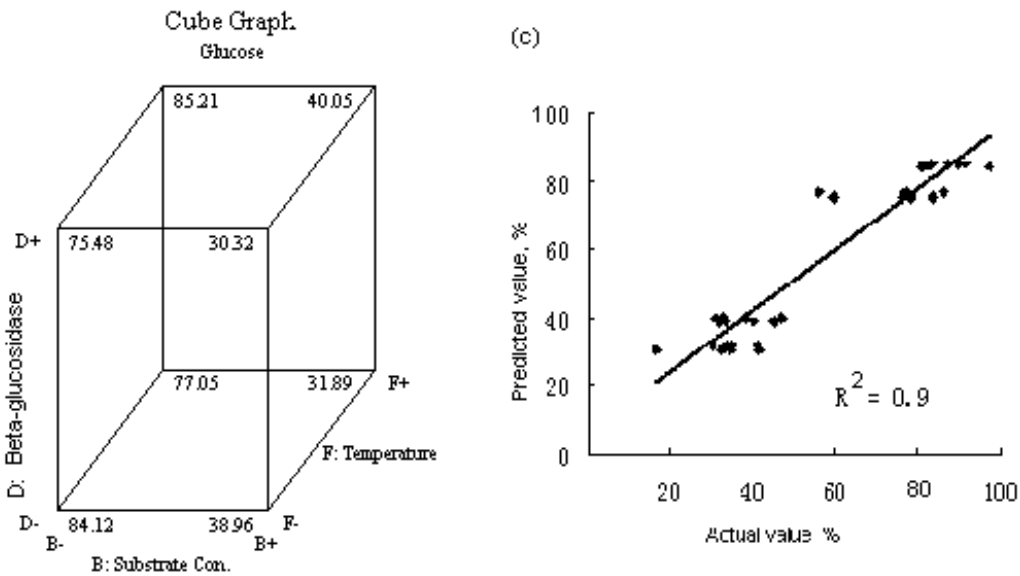

Figure 2: Factorial experimental design applied to BMSW fraction. (a) Factor effects on glucose yield, (b) cube graph of glucose yield, (c) comparison of actual value and predicted value.

\subsection{Waste management}

Using BMSW as resources for bio-ethanol production will reduce the biodegradable fraction from MSW going to Landfill which is one of the requires of EU Landfill Directives. According to the mass balance from the laboratory plant, the amount of waste will be massively reduced by $80 \%$ and the main composition of solid residues from the hydrolysis process are acid insoluble lignin, ash content, protein absorbed and dead cells, which can be used as compost. This technology can be used as an alternative solution. However, Sustainable waste management needs to involve different type of waste management methods in order to minimize the waste produced, and maximize energy/material recovery and to meet the needs of environmentally, economically and socially sustainable. 


\subsection{Climate change}

Ethanol represents the closed carbon dioxide cycle because after burning of ethanol, the released carbon dioxide is recycled back into plant material because plants use carbon dioxide to synthesize cellulose during photosynthesis cycle (Wyman [11]; Chandel [12]). Ethanol production process only uses energy from renewable energy sources; no net carbon dioxide is added to the atmosphere, making ethanol an environmentally beneficial energy source. In addition, the toxicity of the exhaust emissions from ethanol is lower than that of petroleum sources (Wyman [13]). Apart from these, using BMSW as ethanol resources will avoid the biodegradable fraction going to traditional waste disposal plant such as landfill or Incineration, which often causes green gas emissions.

\subsection{Water issues}

A large quantity of water is required for growing energy crops, which causes water shortage problems but there are also cases where there is plentiful water. One of the advantages is that irrigation can increase productivity surrounding plantations. For the ethanol process itself from both BMSW and energy crops, to produce 1 litre ethanol, 4-8 litres of water are required (Lang [14]). And 13 litres of sewage effluent are produced per 1 litre of ethanol produced because of the water that has to be added to the ground corn grain for the fermentation process (Geotimes [15]). Water remains a big issue for bio-ethanol process.

\subsection{Land use}

Growing energy crops for bio-ethanol purposes requires lots of land use. Harvesting corn stover may result in lowering soil organic carbon levels and soil nitrogen content, and may also increase soil erosion (Mann [16]). If agricultural prices are increasingly linked to energy prices then impacts on food security will also be more volatility in the markets. World prices usually account for less than $25 \%$ for any variation at country level. It is currently hard to model effect of biofuels (ODI [17]). Using BMSW as biomass can free the land used for landfill and growing energy crops.

\subsection{Biodiversity}

Input intensive energy crop production involves the movement of agrichemicals, especially nitrogen, phosphorus, and pesticides from farms to other habitats and aquifers. The use of BMSW for bio-ethanol purpose can avoid this problem.

Apart from the environmental impacts discussed above, this BMSW-toethanol system has its economic and social benefits. The end product: bioethanol is a valuable market product, which brings economic benefits from the non-valuable waste and meets the requirement of current energy market demands. However, this process requires the biodegradable waste fraction to be separated from non-biodegradable wastes from the households. The economic benefits with bio-fuel product will encourage waste separation. 


\section{Opportunities of MSW-to-ethanol as an alternative waste management}

Waste management varies from developing nations to developed countries. Under different economic and social environment, different types of waste management methods from re-use, recycle, and energy/material recovery to disposal etc are used. Take the waste management system in London for example: if all London's BMSW available for new recovery options was used for bioethanol production an estimated 346 million litres of ethanol could be produced by 2020 , providing $14.6 \%$ of London's 2004 petrol car consumption. This evaluation should however be considered rough, and further consideration should to be made to a wider range of performance criteria and system requirements.

To realise the potential for bioethanol production requires performance across the lifecycle of the fuel chain against other fuels to be competitive within the end-product (biofuel and wider transportation fuel) market and the feedstock (waste resource) market. Net energy balance, greenhouse gas balance, and production costs are fundamental indicators for sustainable performance. There is a lack of published research examining this in regards to MSW-bioethanol by biochemical processes. Three important areas of research are required:

1. Lifecycle analysis of each of the competing MSW-ethanol technologies converting different BMSW feedstocks;

2. A biofuel lifecycle comparative study which includes the optimum current and future MSW-bioethanol technologies; and

3. A waste management lifecycle comparative study which includes the optimum current and future MSW-bioethanol technologies

\section{References}

[1] European Commission (EC). Directive 2003/30/EC of the European Parliament and of the Council of 8 May 2003 on the promotion of the use of biofuels or other renewable fuels for transport. Official J Eur Union L 123:42-46. 2003.

[2] Defra (Department for Environment, Food and Rural Affairs). Municipal Waste Management. 2006. http://www.defra. gov.uk/environment/statistics/ wastats/index.htm

[3] Mosier N, Wyman C, Dale B, Elander R, Lee YY, Holtzapple M, Ladisch $\mathrm{M}$ Features of promising technologies for pretreatment of lignocellulosic biomass. Bioresour Technol 96:673-686. 2005.

[4] Li, A., Antizar-Ladislao, B., Khraisheh, M. Bioconversion of municipal solid waste to glucose for bio-ethanol production. Bioprocess and Biosystems Engineering. 30(3): 189-196. 2007.

[5] Melander C, Adden R, Brinkmalm G, Gorton L, Mischnick P. New approaches to the analysis of enzymatically hydrolyzed methyl cellulose. Part 2. Comparison of various enzyme preparations. Biomacromolecules 7:1410-1421.2006 
[6] Mandels M, Andreotti R, Roche C. Measurement of saccharifying cellulose. Bioeng Symp 6:21-33.1976.

[7] Paquot M, Thonart P. Enzymatical hydrolysis of regenerated cellulose. Holzforschung 36:177-181. 1982.

[8] NREL (National Renewable Energy Laboratory). SSF Experimental protocols: Lignocellulosic Biomass Hydrolysis and Fermentation. 1995. http://www.devafdc.nrel.gov/pdfs/ 4691.pdf

[9] Ballesteros, M., Oliva, J.M., Manzanares, P., Negro, M.J., Ballesteros, I. Ethanol production from paper material using a simultaneous saccharification and fermentation system in a fed-batch basis. World Journal of Microbiology and Biotechnology 18 (6). 2002.

[10] Gregg, David J., Saddler, John N. Factors affecting cellulose hydrolysis and the potential of enzyme recycle to enhance the efficiency of an integrated wood to ethanol process. Biotechnology and Bioengineering. 51 (4). 1996.

[11] Wyman, C.E. Biomass ethanol: technical progress, opportunities, and commercial challenges. Annual Review Energy Environment 24, 189-226. 1999.

[12] Chandel, A.K., Chan E.S., Rudravaram. R., Narasu, M.L., Rao. L, V., and Ravindra, P. Economics and environmental impact of bioethanol production technologies: an appraisal Biotechnology and Molecular Biology Review Vol. 2 (1), pp. 014-032.2007.

[13] Wyman C.E., Hinman N.D. Fundamentals of production from renewable feedstocks and use as transportation fuel. Appl Biochem. Biotechnol 24/25: 735-75. 1990.

[14] Kathy Lang. Shellulosics - The Next Generation? Canada, 2007.

[15] Geotimes, Weighing in on Renewable Energy Efficiency. August 2005.

[16] Mann L, Tolbert V, Cushman J. Potential environmental effects of corn (Zea mays L.) stover removal with emphasis on soil organic matter and erosion. Agr Ecosyst Environ 89 (3) 149-166. 2002:

[17] Overseas Development Institute (ODI). Biofuels and poverty reduction: Is there a way through the maize? London, UK. 27th June, 2007. 